\title{
Influence of Dietary Vitamin E Deficiency on Compression Injury of Rat Spinal Cord
}

\author{
Yuuji TAOKA, Takaaki IKATA, ${ }^{1}$ and Kenji FuKUZAWA ${ }^{2}$ \\ ${ }^{1}$ Department of Orthopedic Surgery, School of Medicine, Tokushima University, \\ Kuramoto-cho, Tokushima 770, Japan \\ ${ }^{2}$ Laboratory of Health Chemistry, Faculty of Pharmaceutical Sciences, \\ Tokushima University, Shomachi, Tokushima 770, Japan
}

(Received January 19, 1990)

\begin{abstract}
Summary The influences of vitamin E deficiency on compression injury of the rat spinal cord associated with ischemia were investigated. Growing rats were divided into two groups and given a diet containing either $2 \mathrm{IU} / 100 \mathrm{~g}$ or less than $0.1 \mathrm{IU} / 100 \mathrm{~g}$ of $\alpha$-tocopherol acetate, respectively, for 6-8 weeks before experiments. Motor disturbances induced by spinal cord injury were found to be enhanced by vitamin $\mathrm{E}$ deficiency. The spinal cord blood flow (SCBF) was reduced by compression and subsequently increased transiently and then decreased gradually in both groups, but the level was lower in the vitamin E-deficient group than in the control group. After injury, the vitamin E-deficient group showed lower recoveries than the control group in the amplitude and latency of spinal cord evoked potentials and greater pathological changes of the spinal cord, such as bleeding and edema. The increase in the level of TBA-reactive substances in the spinal cord after injury increased with decrease in the dietary level of vitamin $\mathrm{E}$. These results suggest that vitamin $\mathrm{E}$ may have a protective effects against ischemic spinal cord injury by its antioxidant effect.

Key Words vitamin E, tocopherol, spinal cord injury, ischemia, lipid peroxidation
\end{abstract}

After traumatic compression injury of the spinal cord, a series pathophysiological changes, such as ischemia, edema, hemorrhagic necrosis, loss of $\mathrm{Ca}^{2+}$ from the extracellular space, and loss of $\mathrm{K}^{+}$from the intracellular space, have been reported to occur in injured tissue and these lead to destruction and paralysis of the spinal cord (1-4). However, the exact mechanism of the pathogenesis of spinal cord

1 田岡祐二, 井形高明, 2 福沢健治

Abbreviations: SCBF, spinal cord blood flow; SCEP, spinal cord evoked potentials; TBARS, thiobarbituric acid-reactive substances; MDA, malondialdehyde. 
injury is unknown. Recently, cellular damage in ischemia of various tissues, such as the liver, heart, and brain, has been recognized to be at least partly due to increased lipid peroxidation in biomembranes (5-7). Demopoulos et al. (8) suggested that disorders of the central nervous system were associated with abnormalities of free radicals that affected membrane lipids in ischemic tissues. Braughler et al.(9) and Anderson and Means (10) also reported correlations of lipid peroxidation with ischemia due to contusion or compression injury of the spinal cord.

Recently, vitamin $\mathrm{E}$ has been receiving increased attention clinically. Especially, it is reported that vitamin $\mathrm{E}$ has an inhibitory effect on ischemic injury, possibly because of its lipid antioxidant action $(11,12)$. We also have reported that lipid peroxidation is increased in injured spinal cord and that dietary vitamin $\mathrm{E}$ at a higher level effectively protects the spinal cord from compression injury and subsequent lipid peroxidation (13). In this study, we investigated the effect of vitamin $\mathbf{E}$ on experimental compression injury of the spinal cord associated with ischemia in vitamin E-deficient rats by studies on motor disturbances, changes in blood flow, spinal cord evoked potential, and pathological changes after injury. We also measured the levels of lipid peroxides, assayed as TBA-reactive substances, in the spinal cord tissue. The mechanism responsible for initiation and propagation of pathological events in the injured spinal cord is discussed in relation to lipid peroxidation.

\section{MATERIALS AND METHODS}

Animals. Male Wistar strain rats, initially weighing 120-140 g, were given rat chow containing either $\alpha$-tocopherol acetate at 2 IU (control group, C) or less than 0.1 IU (vitamin E-deficient group, D) per $100 \mathrm{~g}$ of diet, respectively, for 6-8 weeks. The chow consisted of $36 \%$ corn starch, $25 \%$ vitamin-free casein, $10 \% \alpha$-starch of wheat, $8 \%$ powdered filter paper, $6 \%$ salt mixture, $5 \%$ granulated sugar, $2 \%$ vitamin mixture, and $10 \%$ stripped corn oil (Eastman Kodak Chemicals). The salt mixture provided $270 \mathrm{mg}$ of $\mathrm{Na}, 692 \mathrm{mg}$ of $\mathrm{K}, 579 \mathrm{mg}$ of $\mathrm{P}, 411 \mathrm{mg}$ of $\mathrm{Ca}, 86 \mathrm{mg}$ of $\mathrm{Mg}, 41 \mathrm{mg}$ of $\mathrm{Fe}, 0.4 \mathrm{mg}$ of $\mathrm{Zn}, 1.3 \mathrm{mg}$ of $\mathrm{Mn}$, and $7.7 \mathrm{mg}$ of I per $100 \mathrm{~g}$ of diet. The vitamin mixture provided $1,000 \mathrm{IU}$ of vitamin $A, 200 \mathrm{IU}$ of vitamin $\mathrm{D}_{2}$, less than $0.1 \mathrm{IU}$ of vitamin $E, 2.4 \mathrm{mg}$ of vitamin $B_{1}, 8 \mathrm{mg}$ of vitamin $B_{2}, 1.6 \mathrm{mg}$ of vitamin $B_{6}$, $0.001 \mathrm{mg}$ of vitamin $B_{12}, 60 \mathrm{mg}$ of vitamin $C, 10.4 \mathrm{mg}$ of vitamin $\mathrm{K}, 0.04 \mathrm{mg}$ of biotin, $10 \mathrm{mg}$ of folic acid, $12 \mathrm{mg}$ of niacin, $12 \mathrm{mg}$ of inositol, $4,000 \mathrm{mg}$ of choline-C1 per $100 \mathrm{~g}$ of diet. Rats weighing about $280-320 \mathrm{~g}$ were used for experiments.

Determination of $\alpha$-tocopherol (vitamin $E$ ) content. $\alpha$-Tocopherol was extracted with ethanol-hexane $(2: 5)$ from sera and homogenates of spinal cord, separated by HPLC on a YMC-PACK A-600-3 column in a Hitachi 655-11 apparatus and measured in a Hitachi-1100 fluorescence spectrometer (14). The $\alpha$-tocopherol contents of the spinal cord and serum before injury were determined 
in 11 rats each of groups $\mathrm{C}$ and $\mathrm{D}$.

Spinal cord injury. All rats were anesthetized by intraperitoneal injection of sodium pentobarbital $(2.1 \mathrm{mg} / 100 \mathrm{~g}$ body weight). Laminectomies were made at the levels of C2 (cervical spine-2) C3, Th12 (thoracic spine-12), and L1 (lumbar spine-1) with a surgical airtome. Trauma was induced by placing a 10, 20, or $40 \mathrm{~g}$ weight extradurally on the spinal cord at Th12 for $5 \mathrm{~min}$. The weight used had a round concave lower surface of $6 \mathrm{~mm}$ diameter and a square top of $2 \mathrm{~mm}^{2}$ area, which exactly fitted the spinal cord.

Grading of motor disturbance. Motor function of the rats subjected to compression trauma was assessed daily for one week after injury. The recovery of the hindlimbs from motor disturbance was graded by Tarlov's criteria (15) as follows: 0 , no voluntary movement; 1 , perceptible movement at joints; 2 , good movement at joints but inability to stand; 3 , ability to stand and walk; 4, complete reovery.

Measurement of spinal cord evoked potentials (SCEP). SCEP were measured before, during, and after compression injury by the method of Inoue (16) with a CADWELL 7400 EMG SYSTEM (AHS-Japan Co.). The electrode for recording (distance between electrodes, $0.3 \mathrm{~mm}$ ) was placed on the posteromedial surface of the dural tube at $\mathrm{C} 2$. The reference electrode was placed at the same level as the recording electrode but in the paravertebral muscle. SCEP were evoked by bipolar supramaximal stimulation (approximately $0.3 \mathrm{~mA}, 6 \mathrm{~Hz}, 0.1 \mathrm{~ms}$ duration) of the posteriomedial dural tube at $\mathrm{L} 1$.

Measurement of spinal cord blood flow $(S C B F)$. The SCBF was measured before, during, and at 30-min intervals after compression injury by the hydrogen clearance method. Hayashi et al. (17) showed that this method was satisfactory when applied to small animals such as rats. An electrode of $80 \mu$ triple Tefloncoated platinum-iridium was inserted into the gray matter through a small hole in the meninges under an operating microscope. The reference electrode was inserted hypodermically into the same region. Then the animal was made to inhale 5 to $10 \%$ hydrogen gas in air through a mask for $5 \mathrm{~min}$, and hydrogen gas clearance was recorded using a 2-channel hydrogen blood flow meter (MT Technical Lab., Tokyo). Clearance curves were plotted semilogarithmically and the blood flow was calculated according to Fick's principle. For measurement of the blood flow during compression injury, the electrode was set in the cavity $0.5 \mathrm{~mm}$ from the center of the weight. High-quality silicone oil was dropped onto the exposed part of the spinal cord to prevent the tissue from drying and to stabilize the electrode. The arterial pressure was maintained at $120 \pm 8 \mathrm{mmHg}$, the $\mathrm{PaO}_{2}$ at $87.1 \pm 4.6 \mathrm{mmHg}$, and the $\mathrm{PaCO}_{2}$ at $38.5 \pm 6.2 \mathrm{mmHg}$. The body temperature was maintained at $36.5^{\circ} \mathrm{C}$ by controlling the room temperature.

Measurement of lipid peroxides. Lipid peroxides in the spinal cord tissues of rats were measured by the method of Ohkawa et al. (18) and expressed as TBAreactive substances (TBARS) in nmol of malondialdehyde (MDA). Approximately $1 \mathrm{~cm}$ of the spinal cord in the Th12 region was removed atraumatically and placed 
in ice-cold $0.9 \% \mathrm{NaCl}$ for measurement of TBARS within $1 \mathrm{~h}$. For the assay, a $10 \%(\mathrm{w} / \mathrm{v})$ tissue homogenate was mixed with sodium dodecyl sulfate in acetate buffer ( $\mathrm{pH} \mathrm{3.5)}$ and an aqueous solution of thiobarbituric acid and heated at $95^{\circ} \mathrm{C}$ for $60 \mathrm{~min}$. Then the mixture was cooled; the pink pigment was extracted with $n$-butanol-pyridine mixture and its absorbance at $532 \mathrm{~nm}$ was measured. Tetramethoxy-propane was used as an external standard, and the level of lipid peroxides was expressed in nmol of malondialdehyde. The level of TBARS was measured before, and $0,0.5,1,2,3,6$, and $24 \mathrm{~h}$ after injury.

Histological examination of tissue injury. The spinal cord was examined histologically $6 \mathrm{~h}$ after compression. Tissues were stained with hematoxylin-eosin. The degree of histological injury of the spinal cord was recorded as the bleeding index:

$$
\text { Bleeding index }(\%)=\frac{\text { area of bleeding }}{\text { area of spinal cord in sagittal section }} \times 100 .
$$

This index was calculated by computed analysis of photographs of histological preparations with an image processing system CB-TASPER (Nachet Co., France).

\section{RESULTS}

There was no significant difference in the mean body weights of groups $D$ and $\mathrm{C}$ at the time of experiments. In groups $\mathrm{D}$ and $\mathrm{C}$, the $\alpha$-tocopherol levels in the spinal cord were $6.0 \pm 1.9(n=11)$ and $11.6 \pm 1.3(n=11) \mu \mathrm{g} / \mathrm{g}$ wet weight, and those in the sera were $1.8 \pm 1.3(n=11)$ and $4.8 \pm 1.5(n=11) \mu \mathrm{g} / \mathrm{ml}$, respectively.

As shown in Fig. 1, one day after spinal cord injury, the degree of motor disturbance was higher in group $\mathrm{D}$ than in group $\mathrm{C}$. The scores for motor function in groups $\mathrm{D}$ and $\mathrm{C}$, respectively, were $2.3 \pm 0.9$ and $3.8 \pm 0.4(n=12, p<0.05)$ after $10 \mathrm{~g}$ weight-compression injury, $1.1 \pm 1.1$ and $2.4 \pm 1.1(n=27, p<0.01)$ after $20 \mathrm{~g}$ weight-compression injury, and $0.8 \pm 1.0$ and $1.0 \pm 1.1(n=31)$ after $40 \mathrm{~g}$ weightcompression injury. Thus the order of motor disturbance was proportional to the compression weight and was increased by vitamin $\mathrm{E}$ deficiency.

Before injury, the mean SCBF was significantly lower in group D $(34.2 \pm 3.2$ $\mathrm{ml} / 100 \mathrm{~g} / \mathrm{min})$ than in group $\mathrm{C}(44.1 \pm 4.0, p<0.01)$. Figure 2 shows the time courses of change in the SCBF during the experiment. After $10 \mathrm{~g}$ weightcompression, the SCBF showed transient increase and then returned to almost the preinjury level in group C, but decreased markedly in group D $3 \mathrm{~h}$ after injury. After $20 \mathrm{~g}$ weight-compression, the SCBF of group D did not return to the initial level and decreased markedly, whereas that of group $\mathrm{C}$ remained at the initial level by $4 \mathrm{~h}$ after injury. Similar results were obtained after $40 \mathrm{~g}$ weight-compression: 6 $h$ after injury, the SCBF of group $C$ was maintained at about $60 \%$ of that before injury, whereas that of group D was only about $47 \%$ of that before injury. 


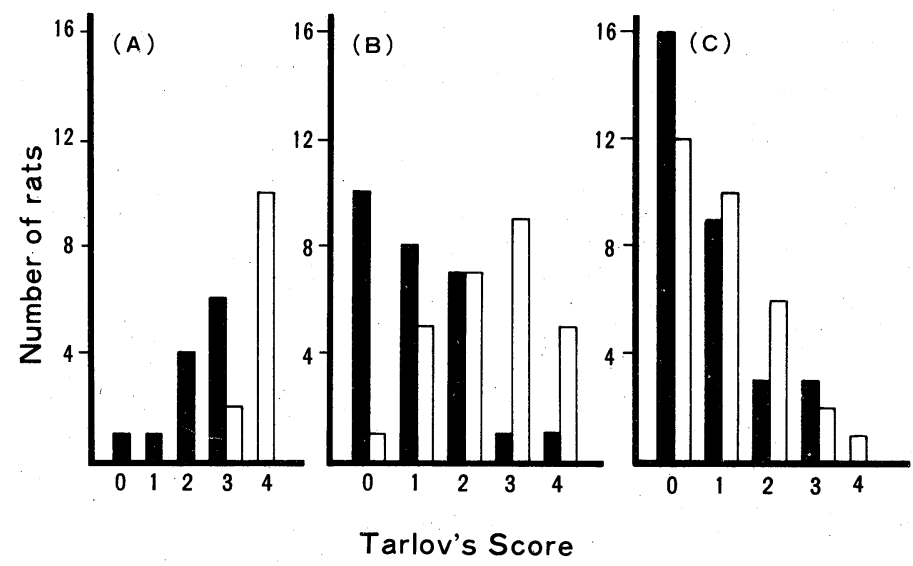

Fig. 1. Influence of dietary vitamin $\mathrm{E}$ deficiency on motor disturbances induced by compression of the spinal cord for 5 min with a weight of (A) $10 \mathrm{~g}(n=12)$, (B) $20 \mathrm{~g}(n=27)$, or (C) $40 \mathrm{~g}(n=31)$. The degree of motor disturbance was assessed one day after compression injury by Tarlov's criteria. $\mathbf{\square}$, vitamin E-deficient group; $\square$, control group.
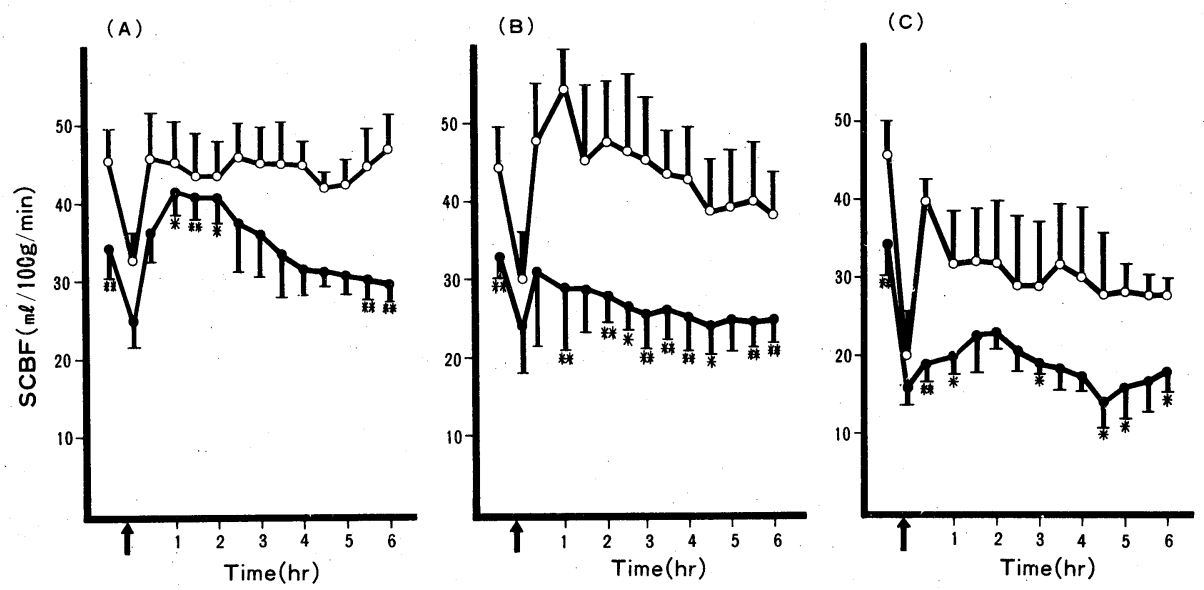

Fig. 2. Changes in SCBF in the gray matter after spinal cord injury by compression for $5 \mathrm{~min}$ with a weight of (A) $10 \mathrm{~g}(n=7)$, (B) $20 \mathrm{~g}(n=5)$, or (C) $40 \mathrm{~g}(n=$ 5). Points and bars are means $\pm S D$. The arrow indicates the time of compression. ๑, vitamin E-deficient group; $\bigcirc$, control group. $* *, *$ Significant differences from corresponding values for the control group at $p<0.01$ and $p<0.05$.

Figure 3 shows the time courses of change in the amplitude and latency of the SCEP. Sixty minutes after $10 \mathrm{~g}$ weight-compression, the SCEP had recovered completely in group $\mathrm{C}$, but the amplitudes and latencies in group D were 70.7 and $119.4 \%$, respectively, of those before injury. Sixty minutes after $20 \mathrm{~g}$ weight- 
(A)
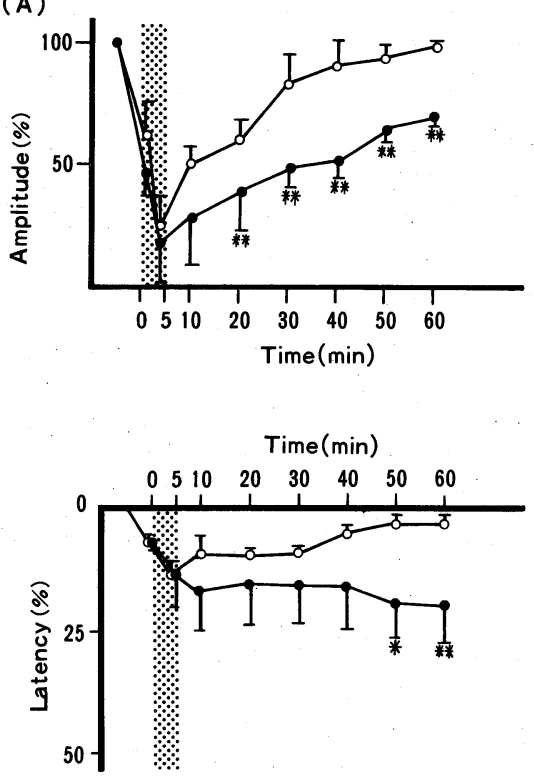

(B)
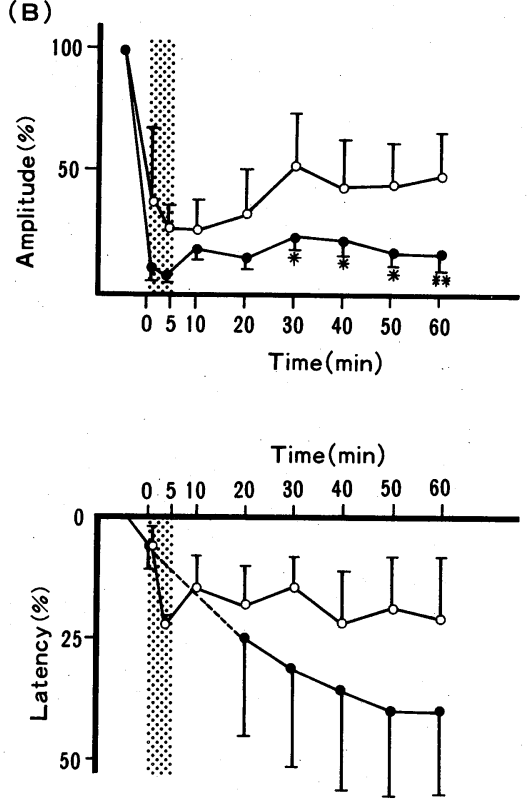

Fig. 3. Changes in the amplitude and latency of the evoked spinal potential by compression for $5 \mathrm{~min}$ with a weight of (A) $10 \mathrm{~g}$ or (B) $20 \mathrm{~g}$. Points and bars are means \pm SD for 5 rats. The shaded zone indicates the time of compression. $\bullet$, vitamin E-deficient group; $\bigcirc$, control group. $* * *$ Significant differences from corresponding control values at $p<0.01$ and $p<0.05$.

compression, the amplitude was $49.1 \%$ of that before injury in group C, but only $17.2 \%$ of that before injury in group D, and the latencies in group C and D were 120.9 and $139.5 \%$, respectively, of those before injury. The SCEP disappeared within $1 \mathrm{~min}$ after $40 \mathrm{~g}$ weight-compression and did not recover in both groups (data not shown).

Figure 4 shows the time course of change in TBARS in the spinal cord tissue after $20 \mathrm{~g}$ weight-compression. The TBARS value of group D increased to a peak of $63.6 \pm 17.8 \mathrm{nmol} / 100 \mathrm{mg}$ wet weight immediately after removal of the weight and remained at a high level for $24 \mathrm{~h}$, whereas that of group $\mathrm{C}$ increased to a peak of $57.9 \pm 4.2 \mathrm{nmol} / 100 \mathrm{mg}$ wet weight $30 \mathrm{~min}$ after injury and then gradually decreased. Figure 5 shows the TBARS levels in the spinal cord tissue $30 \mathrm{~min}$ after spinal cord injury by compressions with 10 and $20 \mathrm{~g}$ weights. As can be seen, the increase of TBARS was proportional to increase of the compression weight and was greatly enhanced by vitamin $\mathbf{E}$ deficiency.

There was no significant difference in pathological findings in group $\mathbf{C}$ and $\mathbf{D}$ before injury, but after injury the areas of hemorrhage were significantly different in the two groups. Quantitatively, the extent of hemorrhage was greater in vitamin E deficiency. The indices $6 \mathrm{~h}$ after compression with 10 and $20 \mathrm{~g}$ weight-compression 


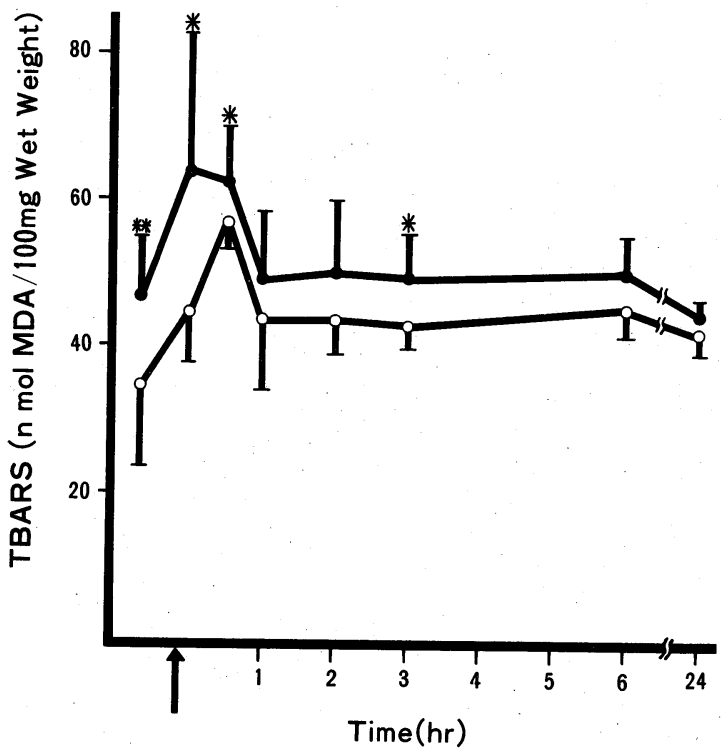

Fig. 4. Changes in TBARS levels in spinal cord tissue after spinal cord injury by compression with a $20 \mathrm{~g}$ weight for $5 \mathrm{~min}$. Points and bars are means \pm SD for 6 rats. The arrow indicates the time of compression. •, vitamin E-deficient group; $\bigcirc$, control group. $* *, *$ Significant differences from corresponding value for control group at $p<0.01$ and $p<0.05$.

were higher in group D than in group C (Fig. 6).

\section{DISCUSSION}

The antioxidant hypothesis of the effect of vitamin E can apparently explain most of the known nutritional and biochemical effects of this vitamin. This hypothesis proposes that unsaturated lipids in tissue are under continuous attack by free radicals and become peroxidized in the absence of vitamin $E$, but that vitamin $\mathrm{E}$ ( $\alpha$-tocopherol) inhibits tissue peroxidation in vivo and in vitro by reacting with free radicals $(19,20)$.

In this present study, we investigated the effect of vitamin $\mathrm{E}$ on experimental compression injury of the spinal cord in vitamin E-deficient rats. Our results showed that motor disturbance induced by compression of the spinal cord was much greater in vitamin E-deficient rats than in control rats. Moreover, we found that vitamin $\mathrm{E}$ deficiency resulted in marked histological and electrophysiological injury of the spinal cord. Decrease in the level of SCBF in the gray matter after injury was also greater in vitamin $\mathrm{E}$ deficiency. The amount of lipid peroxides, estimated as the TBARS value, increased with increase in the compression weight and with decrease in the level of vitamin E intake. Pietronigro et al. (21) and Saunders et al. (22) reported that antioxidants, such as vitamin C, vitamin E, and 


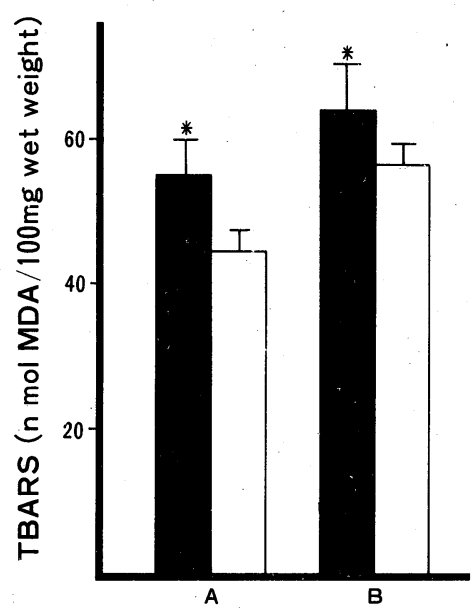

Fig. 5

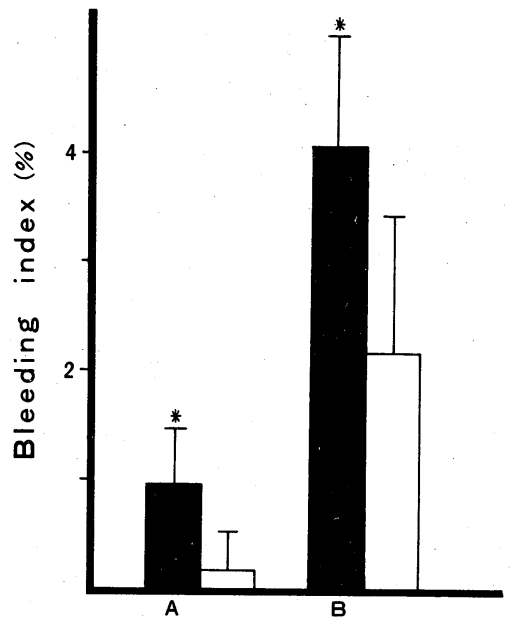

Fig. 6

Fig. 5. TBARS levels in spinal cord tissue $30 \mathrm{~min}$ after spinal cord injury by compression for 5 min with a weight of (A) $10 \mathrm{~g}$ or (B) $20 \mathrm{~g}$. $\square$, vitamin E-deficient group $(n=6) ; \square$, control group $(n=6)$. * Significant difference from control value at $p<0.05$.

Fig. 6. Influence of dietary vitamin $\mathrm{E}$ deficiency on the bleeding index $6 \mathrm{~h}$ after spinal cord injury by compression with a weight of (A) $10 \mathrm{~g}$ or (B) $20 \mathrm{~g}$. Photographs of histological sections were analyzed with an image processing system (CB-TASPER) as described in the text. $\square$, Vitamin E-deficient group $(n=9)$; $\square$, control group $(n=9)$. * Significant difference from corresponding value for control group at $p<0.05$.

Se, have preventive effects on posttraumatic ischemia in the spinal cord. Thus, conversely, vitamin $\mathrm{E}$ deficiency may aggravate spinal cord injury by decreasing inhibition of lipid peroxidation. Consistent with this idea, Anderson et al. (23) reported that the 21-aminosteroid antioxidant $\mathrm{U}-74006 \mathrm{~F}$ was effective against traumatic injury in the cat spinal cord.

Prostaglandin (PG) metabolism is reported to be activated in traumatic injury of the spinal cord (24-26). We also observed imbalance of thromboxane $A_{2}$ (TXA $)$ and prostaglandin $\mathrm{I}_{2}\left(\mathrm{PGI}_{2}\right)$ in compression injury of the rat spinal cord and this alteration was considerably reduced by the selective $\mathrm{TXA}_{2}$ synthetase inhibitor OKY-046 (27). Hayaishi and Shimizu (28) showed that so-called TBARS consist of not only unsaturated hydroperoxy-fatty acid but also PGs. So the increased TBARS levels in the spinal cord after injury observed in our experiment may reflect increases in PGs. Karpen et al. (29) found that vitamin E deficiency raised the platelet level of TXA 2 and lowered the arterial level of $\mathbf{P G I}_{2}$. Thus, in vitamin E-deficient rats the significantly lower SCBF before and after injury of the spinal cord may have been caused by $\mathrm{TXA}_{2}-\mathrm{PGI}_{2}$ imbalance. Further experiments are required to clarify the influences of vitamin $\mathrm{E}$ deficiency on this PG mechanism 
on spinal cord injury.

This work was supported in part by a Grant-in-Aid from the Ministry of Education, Science, and Culture of Japan (No. 01480369 and 02671054).

We thank Eisai Co., Ltd., Tokyo, for generous gifts of control and vitamin E-deficient rat chow.

\section{REFERENCES}

1) Assenmacher, D. R., and Ducker, T. B. (1971): Experimental traumatic paraplegia. J. Bone Joint Surg., 53-A, 671-680.

2) Fairholm, D. J. , and Turnbull, I. M. (1971): Microangiographic study of experimental spinal cord injuries. J. Neurosurg., 35, 277-286.

3) Griffiths, I. R., and Miller, R. (1974): Vascular permeability to protein and vasogenic oedema in experimental concussive injuries to the canine spinal cord. J. Neurol. Sci., 22, 291-304.

4) Stokes, B. T., Fox, P., and Hollinden, G. (1983): Extracellular calcium activity in the spinal cord. Exp. Neurol., 80, 561-572.

5) Marubayashi, S., Dohi, K., Ochi, K., and Kawasaki, T. (1986): Role of free radicals in ischemic rat liver cell injury. Surgery, 90, 184-192.

6) Simpson, P. J., and Lucchesi, B. R. (1987): Free radicals and myocardial ischemia and reperfusion injury. J. Lab. Clin. Med., 110, 13-30.

7) Flamm, E. S., Demopoulos, H. B., Seligman, M. L., Poser, R. G., and Ransohoff, J. (1978): Free radicals in cerebral ischemia. Stroke, 9, 445-447.

8) Demopoulos, H. B., Flamm, E. S., Pietronigro, D. D., and Seligman, M. L. (1980): The free radical pathology and the microcirculation in the major central nervous system disorders. Acta Physiol. Scand. Suppl., 492, 91-119.

9) Braughler, J. M., Duncan, L. A., and Chase, R. L. (1985): Interaction of lipid peroxidation and calcium in the pathogenesis of neural injury. Central Nervous System Trauma, 2, 269-283.

10) Anderson, D. K., and Means, E. D. (1983): Lipid peroxidation in spinal cord. Neurochem. Pathol., 1, 249-264.

11) Yoshida, S., Busto, R., Watson, B. O., and Ginsberg, M. D. (1985): Postischemic cerebral lipid peroxidation in vitro: Modification by dietary vitamin E. J. Neurochem., 44, 1593-1601.

12) Iwasa, H., Aono, T., and Fukuzawa, K. (1990): Protective effect of vitamin E on fetal distress induced by ischemia of the uteroplacental system in pregnant rats. Free Radical Biol. Med., 8, 393-400.

13) Iwasa, K., Ikata, T., and Fukuzawa, K. (1989): Protective effect of vitamin E on spinal cord injury by compression and concurrent lipid peroxidation. Free Radical Biol. Med., 6, 599-606.

14) Taylor, S. L., Lamden, M. P., and Tappel, A. L. (1976): Sensitive fluorometric method for tissue tocopherol analysis. Lipids, 11, 530-538.

15) Tarlov, I. M., and Klinger, H. (1954): Spinal cord compression studies. Arch. Neurol. Psychiat., 71, 271-290.

16) Inoue, Y. (1986): Evoked spinal potentials in Wistar rat. J. Jpn. Orthop. Assoc., 60 , 
777-785.

17) Hayashi, N., Green, B. A., Gonzalez-Carvajal, M., More, J., and Veraa, R.P. (1983): Local blood flow, oxygen tension, and oxygen consumption in the rat spinal cord. $J$. Neurosurg., 58, 516-525.

18) Ohkawa, H., Ohishi, N., and Yagi, K. (1979): Assay of lipid peroxides in animal tissues by thiobarbituric acid reaction. Anal. Biochem., 95, 351-358.

19) Fukuzawa, K. (1986): Site-specific induction of lipid peroxidation by iron in charged micelles and antioxidant effect of $\alpha$-tocopherol, in Clinical and Nutritional Aspects of Vitamin E, ed. by Hayaishi, O., and Mino, M., Elsevier Science Publishing Inc., New York, pp. 25-38.

20) Niki, E. (1987): Antioxidants in relation to lipid peroxidation. Chem. Phys. Lipids, 44, 227-253.

21) Pietronigro, D. D., Hovsepian, M., Demopoulos, H. B., and Flamm, E. S. (1983): Loss of ascorbic acid from injured feline spinal cord. J. Neurochem., 41, 1072-1076.

22) Saunders, R. D., Dugan, L. L., Demediuk, P., Means, E. D., Horrocks, L.A., and Anderson, D. K. (1987): Effects of methylprednisolone and the combination of $\alpha$-tocopherol and selenium on arachidonic acid metabolism and lipid peroxidation in traumatized spinal cord tissue. J. Neurochem., 49, 24-31.

23) Anderson, D. K., Braudhler, J. M., Hall, E. D., Waters, T. R., McCall, J. M., and Means, E. D. (1988): Effects of treatment with U- $74006 \mathrm{~F}$ on neurological outcome following experimental spinal cord injury. J. Neurosurg., 69, 562-567.

24) Jonsson, H. T., and Daniell, H. B. (1976): Altered levels of PGF in cat spinal cord tissue following traumatic injury. Prostaglandins, 11, 51-59.

25) Hsu, C. Y., Halushka, P. V., Hogan, E. L., and Cox, R. D. (1986): Increased thromboxane level in experimental spinal cord injury. J. Neurol. Sci., 74, 289-296.

26) Hsu, C. Y., Halushka, P. V., Spicer, K. M., Hogan, E. L., and Martin, H. F. (1988): Temporal profile of thromboxane-prostacyclin imbalance in experimental spinal cord injury. J. Neurol. Sci., 83, 55-62.

27) Ikata, T., Iwasa, K., Morimoto, K., Tonai, T., and Taoka, Y. (1989): Clinical consideration and biochemical basis of prognosis of cervical spinal cord injury. Spine, 14, 1096-1101.

28) Hayaishi, O., and Shimizu, T. (1982): Metabolic and functional significance of prostaglandins in lipid peroxide research, in Lipid Peroxides in Biology and Medicine, ed. by Yagi, K., Academic Press, New York, pp. 41-53.

29) Karpen, C. W., Merola, A. J., Trewyn, R. W., Cornwell, D. G., and Panganamal, R. B. (1981): Modulation of platelet thromboxane $A_{2}$ and arterial prostacyclin by dietary vitamin E. Prostaglandin, 22, 651-661. 